\title{
Design and Implementation of Virtual 3D Packaging Teaching System Based on 3DMAX
}

\author{
Ling Chen, Xin Yu \\ \{ Ling_visual@163.com\}
}

College of art and designwuchang shouyi university, wuhan 430064, China

\begin{abstract}
Product packaging design is a comprehensive graphic design and threedimensional design work, virtual reality 3D visualization technology and digital virtual interactive technology in the packaging design and application of rapid development. Virtual reality technology in the manufacture of packaging, folding carton, virtual product exhibition plays a role, its characteristics suitable for application in 3D packaging design teaching, so the initiation of the application of virtual reality technology in 3D package design teaching ideas. In this paper, the two part of the content, a part of the digital three-dimensional model of the application of research, that is, digital technology. Three dimensional packaging design mainly studies the packaging carton structure design, packaging design, packaging container design, two-dimensional visual design. According to the characteristics of the teaching of 3D packaging design, the modeling method of 3 dsmax modeling. At the same time, the paper designs and develops a set of virtual 3D packaging design teaching application software. This topic research value lies in: the application of virtual reality technology in the field of packaging design teaching can provide scientific and effective teaching methods for packaging design teaching; to mobilize students' learning initiative and enthusiasm, cultivating study spirit and innovation ability of students, to enable students to adapt to the information age of the packaging design and development mode.
\end{abstract}

Keywords: Virtual reality; virtual interactive technology; 3D visualization; 3D packaging design

\section{Introduction}

Subject to virtual reality technology as the basis, give full play to the immersion of the interactive virtual reality technology characteristics, actively explore packaging design class curriculum construction, teaching methods and interactive virtual platform to build, through the integration of new technology and traditional teaching resources, the traditional teaching mode innovation, enrich and perfect the new era packaging design courses of quality, enhance the packaging design for teaching quality. This topic is to study the three-dimensional packaging design, how to use virtual reality technology to design and realize the threedimensional packaging teaching system [1]. The research includes two parts: one part is the application of the digital three-dimensional model, which is the digital technology. Another part is the research on how to realize the application of digital virtual interactive technology in 3D packaging design. This topic is a kind of new design and demonstration for the teachers and students who are engaged in the teaching of packaging design. Virtual reality (VR), also 
known as "Lingjing technology, is the combination of a variety of technology, modern computer graphics, image processing and recognition, simulation technology, real-time distributed technology, database technology, multimedia technology, multi sensor technology is a cross science and technology. Is the characteristics of this technique. Computer generated an artificial virtual environment, it through computer graphics constitute three degrees of space or to the realistic environment arrangement to the computer to produce a realistic "virtual environment", through the human-computer interaction, virtual environment of visual and auditory experience allows users to immerse themselves in. In 1965, was known as "the father of computer graphics" American scholar Ivan Sutherland published a title as "the ultimate Disply" (literal translation: the ultimate display) of the. In this paper, Ivan Sutherlan idea: a computer screen is to observe the "window" of the real world. In this window can browse the virtual world and the world looks real, moving true, sounds true and feels like real. This paper has triggered a strong interest in virtual reality. From the initial concept put forward, the study on the virtual reality system has experienced nearly 20 years of exploration course, under the impetus of the industrial, military, aerospace science and technology, the idea of Ivan Sutherland has finally become a reality, and achieved a series of achievements. In 1989, Americans formally proposed the term "Reality Virtual (virtual reality)", and made it clear that the purpose of the study of virtual reality technology is to provide a better way than the traditional computer simulation. From then on, "Reality Virtual" has aroused people's great concern and rich imagination.

\section{System Design and Research}

Package design basic course is a combination of theory and practice, the combination of science and art of professional basic courses. Is an important professional basic course in printing engineering, industrial design, art design and other related majors. Purpose of opening this course is training the students' ability of packaging design and master the discipline superb artistic accomplishment and rich performance means, and timely understanding of the development trend of changing economic pulse and packaging design, with independent design and application of theory of the ability of packaging design. Three dimensional visualization (Visualization 3D) technology is a collection of computer data processing, image display technology in the middle of $1980 \mathrm{~s}$. Visualization is the base of virtual reality technology, its development has produced virtual reality technology, virtual reality technology is the advanced stage of visualization technology. Three dimensional visualization is a kind of image display tool, which is used to display the features of design and external visual design. It can make teachers and students understand the characteristics and organizational structure of 3D packaging design [2].

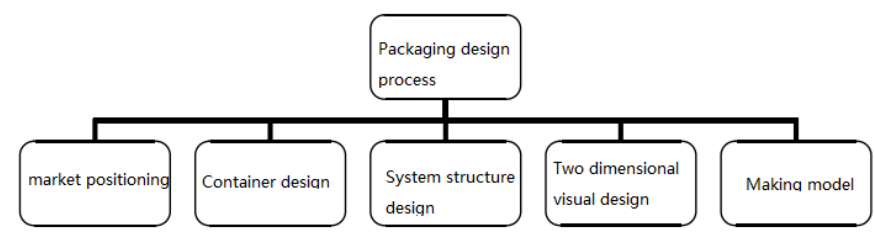


Fig. 1. Packaging design flow chart

\subsection{Virtual Reality Technology Analysis}

The development history of virtual reality technology can be traced back to eighteenth Century. In 1990, the main technology of the virtual reality in the international conference held in Dallas in the United States is defined as the main technology of the virtual reality: real time 3D graphics generation technology, multi sensor interaction technology, high resolution display technology. Virtual reality technology system includes input and output devices, such as head mounted displays, stereo headphones, head tracking system and data glove; virtual environment and software, to describe specific virtual environment dynamic characteristics, structure and interaction rules, etc.; external equipment of the computer system, graphics, sound synthesis device and the like three main parts. Structure design of packaging is packaging engineering specialty as a practical strong professional and technical basic courses, is also a printing engineering, industrial design, art design and other related professional packaging a important professional basic courses. Packaging design mainly studies the carton design, packaging design, packaging design, packaging 2D visual design, packaging materials application and packaging printing process perspective of a comprehensive system of learning [3].

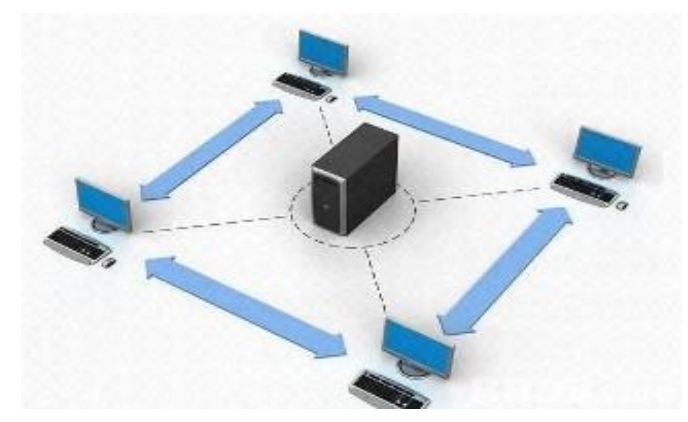

Fig. 2. Sketch map of virtual display technology

\subsection{System Teaching Design}

Packaging design teaching content is divided into: 1 . The packaging design of the market positioning, two. Carton packaging structure design, three. Packaging design, packaging design, four. Two-dimensional visual design, five. Packaging materials and technology. In this paper, the design and research of chocolate packaging products, including the main content and form of product packaging design. At present, the teaching of packaging design is selected to use multimedia display ppt courseware. Knowledge content mainly through pictures, text display; packaging design works mainly through the two-dimensional design software to complete, although some software of 3D packaging design also strongly want to embody the vivid, lifelike products packaging design effect, but the packaging design and virtual system ratio, convenient and vivid, intuitive and also the difference between the very far. Content design according to the results of the needs analysis to define the results of the system to show the role of the definition and division of the function module. Interface design of the system for the user interface design of the core ideas and design concepts, and in accordance with the theoretical production of the user interface display. Organizational structure design for the 
system production completed and delivered to the project file organization structure, according to module and the whole framework design of framework of the core document, logical file and data file organization structured, structured directory classification and storage. Prototype design data, will be of this system by the use of various types of data, such as 3D model data, packaging style data, prototype design, to achieve the greatest degree of multiplexing, is convenient for the system function expansion [4].

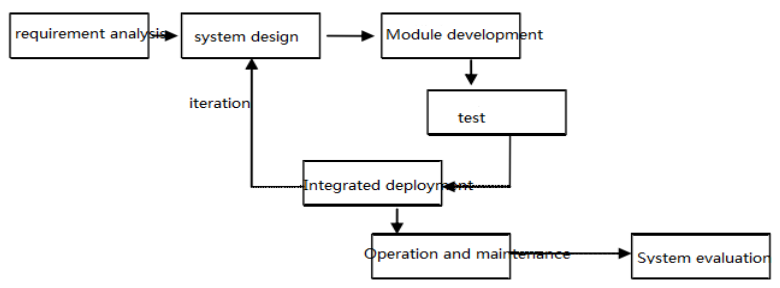

Fig. 3. Flow chart of system design

\section{System Design and Implementation}

The core development of Sun3D SDK Sun3D, commonly known as an engine for Sun3D. It consists of many of the core libraries (DLL) and the application program interface (API) composition, it is like a car engine as, the core driving force for the operation of the whole system, all applications must call its function interface. SDK Sun3D development kit can be used across the platform, it can run on Microsoft's Windows platform, can also run on Apple's IOS platform, you can also run on Google's Android platform. That is to say, using Sun3D SDK to develop the game and virtual demonstration projects such as both can be run in the windows desktop computer, you can also run on apple I pad, the I phone, can also run on the Samsung Android phone. By Sun3D SDK (software development package to develop the web version of the application program can also in various browsers running, such as IE browser (Internet Explorer, Firefox browser (Firefox explorer, Google Chrome (Google Explorer), apple (opera browser, 360 security full browser (360 Explorer). SUN3D is suitable for all kinds of platform development, the system generated files are based on the web page design. That our system can establish the advantages of network links, SUN3D engine development of the document is very small amount of data, but also easy to network transmission, but also for large databases and expand the possibility of convenience. Teachers in the PPT courseware design process and the effect of teaching is also a picture show, three-dimensional structure of the characteristics of the modeling and image representation is difficult to specific. If you want to model replacement effect of packaging design must be redesigned; students in practice need to devote more time to make the packaging three-dimensional renderings, the physical production is spend more time and energy to do a for the production of objects. If you want to change the shape and the outer packaging design to complete the above design steps, not only cumbersome, but also the design effect can not be real-time review. We can look at the system interface of the three-dimensional packaging of chocolate packaging design, through the system interface to provide the buttons and loading. In teaching and learning can be interactive control of the modelling of the different models and transform mapping, the method and content of design form is very intuitive; students to do exercises, set the specifications of 
packaging design can get a series of design and loading in the system program can conveniently browse the three-dimensional design works for students. In this way, students do not have to spend energy, to do three-dimensional effect drawing and physical production. It is beneficial for students to focus on the product packaging design [5].

\section{Conclusion}

The application of virtual reality technology in the teaching of packaging design is a kind of innovation, which provides a scientific and effective teaching means for packaging design teaching. Its immersive interactive features show the teaching content in various forms and multi angles, and interact with the main body directly in the virtual scene, and vividly display the teaching content. To provide scientific and effective teaching methods for packaging design teaching, enhance students' interest in learning and innovation ability, so that students can adapt to the information age of packaging design research and development model. This topic can also for other professional development of new virtual reality teaching platform provides reference and make a contribution to the teaching method reform under the background of new era.

\section{References}

[1] Huang Huang. Semantic level. packaging engineering for interactive design. No. 02. (2013)

[2] Song health. Packaging specialist - Visualizer. printing world. No. 07. (2011)

[3] Zhao Jiuming, Li Shiguo. Research on the user experience of virtual product packaging under the network environment. packaging engineering. No. 02. (2011)

[4] Zhou Shubao, Wu Yan, Han Jianliang. The method of digital product packaging design based on Web3D and the implementation of. Publishing and printing. No. 04. (2010)

[5] Hall. Based on the SolidWorks of the structure of the packaging container design and implementation of. Packaging engineering. No. 15. (2010) 